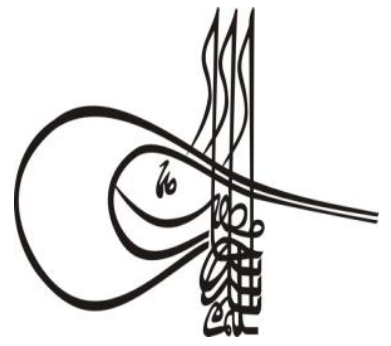

Received/Geliş: 10.08.2019
Turkish Studies

Volume 14 Issue 6, 2019, p. 3009-3020

DOI: 10.29228/TurkishStudies.30201

ISSN: $1308-2140$

Skopje/MACEDONIA-Ankara/TURKEY

Research Article / Araştırma Makalesi

ArticleInfo/Makale Bilgisi

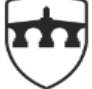

INTERNATIONAL BALKAN UNIVERSITY

EXCELLENCE FOR THE FUTUR IBU.EDU.MK

$\checkmark$ Accepted/Kabul: 15.10 .2019

Go Report Dates/Rapor Tarihleri: Referee 1 (08.10.2019)-Referee 2 (11.09.2019)

This article was checked by iThenticate.

\title{
KİTSCH ÜZERİNE BİR İNCELEME: KİTSCH MÜZİK
}

\author{
R. Görkem AYTIMUUR*
}

\begin{abstract}
ÖZ
$\mathrm{Bu}$ çalışmada Kitsch kavramının genel yapısı göz önünde bulundurularak, müzikteki yerinin ne olduğu incelenmiştir. Bu anlamda Kitsch’in, müzik alanında bir karşıllğının olup olmadığ güzel sanatlarla ilişkilendirilerek temellendirilmiștir. Kitsch, güzel sanatların değișik alanlarında kendini endüstriyel kültür ürünleri olarak açımlamaktadır. $\mathrm{Bu}$ sanat alanları içinde, Kitsch, kültürün kolay ulaşılabilir, ucuz, kitlelere dönük ve taklit üretimleri olarak karşımıza çıkmıştır. Çalışmanın bağlamı gereği, benzer üretim biçimlerinin müzik alanında da olup olmadığı incelenmiş, böyle üretimlerin olası formlarının ve yapısının ne olduğu belirtilmiştir. Öncelikle Kitsch kavramının güzel sanatların farklı alanlarındaki yeri ve yapısı, genel bir çerçeve içinde açıklanmıştır. Bu genel çerçevede kavramın terimsel kökeninden başlayarak tarihsel arka planı incelenmiş, Kitsch'in yerleşik bir sanat geleneği ile olan ilişkisi ifade edilmiştir. Gerçek sanatla Kitsch arasındaki parazitsel ilişkinin endüstriyel ve taklit üretimlere nasıl dönüştüğü açıklanmıştır. Çalışmanın sonraki aşamasında ise müzikte Kitsch kavramı üzerine bir inceleme gerçekleștirilmiștir. 'Kitsch Müzik' olarak ifade edilmiș üretimlerin temel özellikleri ve yapıları ele alınmıș, bu müziğin hem popüler müzikle olan ilisskisi hem de ciddi müzik alanındaki yeri belirtilmiștir. Bu anlamda müzik endüstrisi ile Kitsch'in ortak bir proje yürüterek, yapay bir müzik kültürünü nasıl yapılandırdığı ifade edilmiş, bu taklit üretimlerin kültür endüstrisi içindeki yeri ve yapısı incelenmiştir. Özetle, bu çalışmada Kitsch müziğin ne olduğu açıklanmıştır.
\end{abstract}

Anahtar Kelimeler: Kitsch, Müzik, Güzel Sanatlar, Müzik Endüstrisi. 


\title{
A REVIEW ON KITSCH: KITSCH MUSIC
}

\begin{abstract}
In this study, considering the general structure of Kitsch concept, its place in music is examined. In this sense, whether Kitsch has an equivalent in the field of music is based on associating with fine arts. Kitsch presents itself as industrial cultural products in various fields of fine arts. Within these fields of art, Kitsch is emerged as an easily accessible, inexpensive, mass-oriented and imitation product of culture. In this context, it has been examined whether similar forms of production are in the field of music, the possible forms and structure of such productions are stated. In this study, first of all, Kitsch concept and its structure in different fields of fine arts are explained in a general framework. Within this general framework, starting from the term's origins, the historical background of the concept is examined and its relationship with the established art tradition is expressed. It is explained how the parasitic relationship between real art and Kitsch has turned into industrial and imitation productions. In the next stage, an examination of the concept of Kitsch in music was conducted. The main features and structures of the productions which are expressed as 'Kitsch Music' are discussed. In this sense, the relationship between Kitsch music and popular music as well as its place in serious music are mentioned. By conducting a common project with the music industry, it is stated how it structured an artificial music culture, and the place and structure of these imitation productions in the culture industry is examined. In summary, the aim of this study is to explain what Kitsch music is.
\end{abstract}

\section{STRUCTURED ABSTRACT}

In this study, considering the general structure of Kitsch concept, its place in music is examined. In this sense, Kitsch is based on whether or not there is a counterpart in the field of music.

Kitsch appears as industrial productions nurtured from different fields of fine arts. It is a concept that is used to express imitation productions that are easily accessible, inexpensive and directed to the wishes of the masses within the mass culture. In this study, it is examined whether a similar approach to these forms of production, which is related to Kitsch in fine arts, exists in music.

For the art world, Kitsch marks a series of imitations and productions. The main purpose of this study is to examine whether kitchin is an expression used in the field of fine arts or not in musical productions. The possible forms and the structure of such a production are discussed, so that the concept of its Kitsch music olan which is a summary expression of the conceptual framework of the study is explained. In this context, firstly, the structure of Kitsch concept and its relation to fine arts have been stated and in this way, from art to the music field which is the main area of the study, a theoretical approach has been advanced. Thus, this study, which questions the Kitsch structure and mode of production, reveals the importance of the study in 
terms of originality and literature, since it is oriented towards less studied music than other fields of art.

In the study, a literature-based study on Kitsch ranging from the general art to the music was conducted. Considering the basic studies written on this subject, a limited number of studies on music have been reached. As a method, Kitsch is discussed comparatively with its place in fine arts and music. In this way, a Kitsch concept which is consistent with the equivalent of fine arts is aimed to be reached through music.

The main feature of Kitsch music is that it focuses on the issues of human emotion. In this way, Kitsch music serves life and is oriented towards people. Because of this orientation, Kitsch music has been described as a propaganda tool. The instrumentalization of this music stems from its easy-to-understand structure, far from a deep expression. This is the structure needed for advertising culture. In fact, Kitsch music is more about one's mind than emotions. This made it easier for the cultural industry to transform Kitsch music into a propaganda tool to influence the masses.

A common feature of Kitsch that is common to fine arts and music is that it emulates or imitates a tradition. Kitsch relates the examples he imitates or copied through his descriptive or symbolic features. In this context, it is possible to say that the direction imitated by a production to be expressed as Kitsch can be clearly described in the work of art which is the source of imitation. However, it is not easy to reveal these descriptions or representations in abstract art or in the structure of music itself. However, this does not mean that there are no descriptive elements in abstract art or music.

Another feature of Kitsch music is the character of simplicity, especially in popular music. In this sense, it is possible to list the following features of kisch regarding its appearance in this kind of music: effect.

- Contains repetitive music episodes or lyrics that create a hypnonic

- Uncomplicated, less form and simple harmonic array structures.

- Using simple and repetitive digital infrastructures.

- Using vocal sounds that are brought to the front of the music infrastructure with technological means.

As a result, it can be said about the structure of Kitsch related to fine arts and music:

Kitsch is a phenomenon in the important facts about the cultural life of the 20th century. It is also possible to say that the origin of Kitsch dates back to the 20th century. Such a production is made by establishing a parasitic relationship with an established art tradition of fine arts. It appears as a sloppy, simple and imitated product that serves the financial relations of mass culture of a real art field. It is mostly used in decorative products. It is characterized by exaggerated ornaments and excessive emotional expressions. It is easily accessible financially by large masses. Another reason for the masses' Kitsch orientation is that they are easy to understand. Kitsch is tangible and symbolic, and this structure is shaped according to the feelings and desires of the potential 
buyer. Finally, it is necessary to say that keeping Kitsch with bad art is not the right approach. In this context, not every bad art except the mentioned qualities is Kitsch.

In the field of music, Kitsch is a phenomenon that reveals its existence as in fine arts. However, due to the concrete and symbolic nature of Kitsch, examples related to fine arts in music

Keywords: Kitsch, Music, FineArts, Music Industry.

\section{Giriş}

"Kitsch (Kiç)" teriminin kökeninin Almanca olduğu düşüncesi oldukça yaygındır. Daha önce Fransızca'da kullanılmış olan "art de pacotille (abur cubur)"e karşıllk gelen bu terim, günümüzde Almanca'da olduğu gibi, tüm Avrupa dillerinde de "Kitsch" olarak kullanılmaktadır. Sifat olarak kullanıldığında Kitsch veya Kitschy, kitleler için amaçlanan ve onlar tarafindan takdir edilen kültürel ürünleri nitelemektedir. İsim olarak kullanıldığında ise bir estetik düşünceyle kesin bağlantısı olduğu halde, daha çok etik bir kategori olarak tanımlanmaktadır. Bu anlamda Kitsch için hem 'mutluluk sanatı' hem de 'haz alma ile ilgili kötü bir sanatsal deneyim' ifadesini kullanmak mümkündür. Kitsch bu bağlamıyla kolay erişilebilirlik için daha çekici olma konusunda bir modeli ifade etmektedir.

Kitsch'in varoluşunun tamamen meşrulaşması hala tartışılan bir konudur ancak bir toplumun kültürel üretimlerinin aynı zamanda seri ve hızlı bir şekilde tüketilen metalarla olan ilişkisini tanımlama konusunda önemli bir ifadedir. Bu anlamda Kitsch, sıradan insanın elitizm karşısındaki, vasatlığın entelektüelite üzerindeki ve herkese ulaşabilen bir sanat anlayışının azınlık bir sanat çevresi karşısındaki zaferini işaret etmektedir. Bu zaferi bir değişim süreci olarak ele aldığımızda, modern bir estetikten, yavaş yavaş her şeyi sanatın konusu olarak ele alabilen post-modern bir anlayışa geçiş sürecinden söz etmek mümkündür.

Kitsch güzel sanatların değişik alanlarından beslenen endüstriyel üretimler olarak karşımıza çıkar. Kitle kültürü içinde kolay ulaşılabilir, ucuz ve kitlelerin isteklerine yönelmiş taklit üretimleri ifade etmek için kullanıla gelmiş bir kavramdır. Bu çalışmada da Kitsch'in güzel sanatlarla ilişkili olan bu üretim biçimlerine benzer bir yaklaşımın, müzikte de varolup olmadığı incelenmiştir. Böyle bir üretimin olası formlarının ve yapısının ne olduğu ele alınmış, böylece çalışmanın kavramsal çerçevesinin özet bir ifadesi olan 'Kitsch müzik' kavramının ne olduğu açıklanmak istenmiştir. Bu bağlamda öncelikle Kitsch kavramının yapısı ve güzel sanatlarla ilişkisi belirtilmiş ve bu şekilde sanat genelinden, çalışmanın temel alanı olan müzik özeline, kuramsal bir yaklaşımla ilerlenmiştir.

\section{Kitsch Kavramının Yapısı ve Güzel Sanatlarla Olan İlişkisi}

Kitsch ile ilgili ilk merak edilen konu ne zaman ortaya çıktı̆̆ıdır. Günümüzde en yaygın düşünce onun endüstri devrimiyle birlikte ortaya çıkmış ve moderniteyle sırt sırta bir olgu olduğudur. Bununla birlikte Kulka (2014), kavrama sosyol-kültürel anlamda yaklaşan yazarların Kitsch'in geçmişini moderniteden de önceki zamanlara dayandırdıklarından söz etmektedir. Yine Kitsch'e estetik ve biçim olarak yaklaşan bir başka bakış açısı da onu romantizmin bir ürünü olarak görme eğilimi içindedir. Duygusal yapısı ve dramatik etkisi göz önüne alındığında, Kitsch ile romantizm arasında ilişki kurmak mümkün olsa da onun geçmişini romantizmle sınırlandırmak da doğru değildir.

Konu üzerine yapılan çalışmalardan anlaşıldığı kadarıyla, bu kavramın geçmişi sanatın geçmişi kadar eski zamanlara dayanmaktadır. Ancak Clement Greenberg gibi araştırmacılar Kitsch'i modernite ile eş zamanlı görmekte ısrarcıdırlar. Bu ısrarın temel sebebi, endüstri devrimiyle birlikte bu türdeki üretimlerin sayısının büyük miktarda artmış olmasıdır. 
20. yy'ın başlarıyla birlikte geleneksellikten kopmak avant-garde düşüncenin temel niteliğindedir. Bu süreçle birlikte toplumsal yapıdaki değişim de kaçınılmaz olmuştur. "Kitsch, Batı Avrupa ve Amerika'daki toplumları şehirleştiren ve evrensel okuryazarlık anlayışını getiren endüstri devriminin bir ürünüdür" (Greenberg, 2015: 46). Endüstri devrimi kültürü yeniden tanımlamıştır. Tarlalardaki işçiler şehirlere göçmüş ve tanıdıkları bir kültür yaşantısı için özlem duymuşlardır. Bu da Kitsch'in üretimine uygun toplumsal talebi oluşturmuştur.

Proletarya ve küçük burjuva olarak şehirlere yerleşen köylüler etkin olma adına okuma ve yazmayı öğrenmişler fakat şehrin geleneksel kültüründen zevk almak için gerekli olan boş zaman ve konforu elde edememişlerdir. Arka planı kırsal kesime dayanan, halk kültürüne ait zevklerini kaybeden ve aynı zamanda sıkılmak için yeni bir alan keşfeden bu yeni şehirli topluluk kendi tüketim anlayışlarına uygun bir kültür sağlaması için toplum üzerinde bir baskı oluşturmuştur. Bu yeni piyasanın taleplerini karşılamak için yeni bir ürün tasarlanmıştır: yapay kültür, yani kitsch. Bu yapay kültür, has kültürün değerlerine duyarsız fakat yine de bir çeşit kültürün doyurabileceği bir açlığa sahip olanlar için üretilmiştir. (Greenberg, 2015: 47).

Avrupa'da seri üretimin ortaya çıkışıyla birlikte, duygusal ve gösterişli bir sanat anlayışının kültürel bir yansıması olarak Kitsch kavramı ortaya çıkmıştır. Bu kavram kitlelere satılacak sanatı, açıkça bir zevk unsuruna dönüştürmüştür. Terim olarak, 1860'larda, Münih'te, tüccarlar tarafindan, ucuz olan sanata atıfta bulunmak için kullanılmış ve 1920'lerde Avrupalılar tarafından evlerine kadar kabul edilmiştir. Kitsch, bu süreçle birlikte popüler kültürün totaliterliğini eleştiren yazarlar tarafından yaygın olarak kullanılmaya başlanmıştır. Sosyolojik bağlamda ele alındığında, terimin duygusal tembellik ve kendini aldatma çağrışımları, sanat geleneğiyle ile kurulan parazitsel ilişkisi olarak görünüme gelmiştir.

Kitsch’in etimolojisine dair akademisyenler arasında bir görüş birliği yok. Bazıları kelimenin, Almanlar tarafından yanlış telaffuz edilen, İngilizce'deki 'sketch', kelimesinden türediğini iddia ediyor, bazılarıysa kelimenin Almancadaki 'verkitschen (ucuzlatmak)' fiilinden geldiğini söylüyor. Ludwig Giesz, 'Kitsch', kelimesinin kökeninin Almanca 'Kitschen', fiilinden geldiği konusunda 1srarc1; fiil 'den Strassenschlam zusammenscharren', yani 'sokaktan toplamak', anlamina geliyor. Kitsch kelimesinin Fransizca 'chic' kelimesinden türediği yönünde bile spekülasyonlar vardır (Kulka, 2014: 32).

Kitsch kelimesinin kaynağı ne olursa olsun, olumsuz bir üretim biçimini işaret ettiği düşüncesi ortak bir kanıdır. Düşük kalitede bir üretimi ya da gösterişli olmakla birlikte, niteliksiz bir üretimi ifade etmek için bu terim kullanıla gelmiştir. Kötü sanatı anlatmakta Kitsch'in kullanımı oldukça yaygındır. Ancak Kulka'ya (2014) göre Kitsch, hiçbir şekilde 'kötü sanat'la, eş anlamlı değildir. Kitsch kötü olsa bile, tüm kötü sanatlar Kitsch değildir. Kavramı, aşırı duygusal, aynı zamanda da derinlikten ve entelektüel bir bakıştan uzak üretimlerle bir tutma eğilimi, günümüzde de hala geçerlidir.

Belli bir dönemin sanat geleneğine öykünen hatta taklit eden Kitsch, kendi üretim döneminin baskın sanat anlayışlarıyla ilişkisiz bir görünümdedir. Kitleler tarafından rahatça ulaşılabilirliğinin altında kolay algılanabilir olması, seri olarak üretilebilmesi ve finansal anlamda erişilebilir olması yatmaktadır. Bu, aynı zamanda onun popülerleşmesini açıklayan formülüdür. Büyük kitlelere ulaşabilmesi, onları etkileyebilme konusunda Kitsch'e firsat sağlamıştır. Ticari anlamdaki tüketim değeri ona, ciddi sanatsal üretimlerle rekabet etme olana sağlamıştır. Kitsch büyük kitlelerce sevilmiştir çünkü derin bir entelektüeliteden uzak ve ortak duygulara yönelen üretimleri temsil etmektedir. Alıcısının duygularını yoğun bir şekilde harekete geçiren Kitsch'in, büyük kitleleri etkileyen bir diğer özelliği de kullandığı reklam dilidir. Endüstriyel ürünlerin reklamlar aracılığıyla büyük kitleleri etkileyen hitap yeteneği, Kitsch'in pazarlanma gücünü açığa çıkarmaktadır. Kitsch'in aynı gücü siyasi ideolojilerin büyük kitleleri etkilemesinde de kullanılmıştır. Kulka'ya (2014) göre, Hitler ya da Stalin'in kendi ideolojilerini dikte etmelerinde Kitsch'i bir araç olarak kullanmalarının arkasında da bu özelliği yatmaktadır.

\section{Turkish Studies}

Volume 14 Issue 6, 2019 
Ucuz dekorasyonun bir temsili olarak nitelendirilen kitsch sadece şehirlerle sınırlı kalmamış, yaygın bir üretim biçimini ifade etmiştir. Bu süreçte coğrafi, kültürel veya etnik sınırları aşmıştır. Kitsch için asal olan parazitsel ilişki kurup, taklit edebileceği yerleşik bir sanat geleneğinin var olması ve endüstri içindeki satış değerinin öncelenmesidir. Kitsch, materyal olarak orijinal kültürün zenginliklerinden yararlanır ve onları taklit eder. Bu anlamda Kitsch eski, geleneksel formların ve kendi bağlamından uzaklaşan biçimsel bir dünyanın boş süslemelerinin yansıtılmasıdır. "Kitsch bir nostalji unsuru olarak, geçmişi şimdiki zamanda daha fazla yaşatmak için, yanlış anılan bir geçmişi çağırmaktadır. Kitsch, bir şeyi değiştirmek değil, şimdi ve burada olan bir şeyi daha kabul edilebilir kılmak için bir teselli sunar" (Morris, 2013: 27). Kitsch bu anlamda mekaniktir ve formüllerle çalışmaktadır. Açıkça bir taklit işidir. "Karakteristik olarak, Kitsch, daha yüksek kültür biçimlerinde bulabildiği her şeyi bir meta olarak kullanır, klasik motifleri kolayca kendi içine yedirir, bir taklite dönüştürür" (Babilas, 2014: 116). Kitsch, sanat alanının türüne göre değişirse de sahte olan her üretimin özüdür. Endüstri tarafında üretilen bu taklit ürünler, pazar için hazırlanmış birer metaya dönüşmüşlerdir.

Kitsch aldatıcıdır. Birçok farklı seviyesi vardır ve aralarından bazıları kendi doğru yolunu arayan naif bir birey için yeterince tehlikeli olabilecek yüksekliktedir. Mesela lüks mallar ticareti için yüksek sınıf bir kitsch olan New Yorker dergisi, büyük ölçüde avant-garde malzemeden yararlanır. Bu demek değildir ki Kitsch'in bütün ürünleri değersizdir. Zaman zaman otantik halk kültüründen tatlar barındıran değerli şeyler ürettiği de olur ve bu tesadüfi ve istisnai örnekler birçok insanın aldanmasına sebep olmuştur (Greenberg, 2015: 48).

Kitsch'i açıklayan bir başka özelliği de somut, simgesel ve betimsel olana yönelmiş olmasıdır. $\mathrm{Bu}$ aşamada Kitsch'in yerleşik bir sanat geleneğine öykündüğü ve onu taklit ettiğini tekrar belirtmek gerekmektedir. Söz edilen bu sanat geleneği içinden duygulara yoğun bir şekilde yönelen, hatta onları harekete geçiren unsurlar seçilir ve Kitsch'in temel içeriği oluşturulur. Bu içerikler büyük kitlelerce onaylanmış hali hazırdaki somut duygularla eşleştirilir. Bu anlamda Kitsch'in iç̧eriği kolayca betimlenebilir niteliktedir. Kitsch'de olası alıcısını rahatsız edecek ya da kafasını karıştıracak unsurlar yoktur. Kitsch kolaylıkla tanımlanabilir ve kolay iletilebilir konularla yapılandırılır.

Theodor W. Adorno ve Max Horkheimer 1930'larda kitle kültürünün tüketim alışkanlıkları ve üretim biçimlerini tanımlamak üzerine 'Kültür Endüstrisi' kavramını ortaya çıkarmışlardır. Kültür endüstrisinde temel olarak tüketicinin istediği kolay ve seri tüketime uygun ürünler pazara sürülmektedir. Bu ürünlerin alıcısıyla kurduğu haz ve eğlence ilişkisi, yanlış bilinci doğuran bir kitle kültürünü ortaya çıkarmıştır. Adorno için, kitlesel estetik, insanlık dışı kitlesel üretim yöntemlerini toplumdaki gerçek sorunların önemsizleştirilmesiyle birleştiren kültür endüstrisinin özüdür. Büyük kitleler sadece rahatlamak uğruna sanatsal üretimlerin niteliğini bir eğlence endüstrisi düzeyine indirgemişlerdir. Kitsch de Adorno için böyle bir üretim ilişkisinin ürünüdür. Yeni ya da avant-garde bir sanat düşüncelerini, sahte bir sanat pazarında Kitsch üretimlere yönelmiş tüketicinin anlamasındaki yetersizliğinin nedeni, kültür endüstrisi tarafindan yönetilen, boş zaman etkinliklerinin belirlendiği sosyal koşullardan kaynaklanmaktadır. Kitsch, samimiyetsiz, türetişmiş bir taklit, tekrarlayan veya bir şekilde gerici ideolojiyle dolu bir propaganda aracı olarak hizmet etmektedir. Toplum üzerindeki etkisi, özellikle gençlere yönelik olarak ele alındığında zararsız bir şey olmaktan çok uzaktadır. "Halkın Kitsch istediği iddiası sahtekârlıktır. İnsanların gevşemeye gereksinim duydukları ile ilgili iddia, net değildir. İnsanların enerjileri, daha insancıl bir özniteliğe yol açabilecek etkilerden uzaklaşmaktadırlar. Burada esas olarak anlaşılması zor olan gerçek bir sanatın hakikat içeriğidir" (Adorno ve Leppert, 2014: 95).

Kitsch'le ilgili şimdiye kadar yapılan açıklamaları Kulka şu şekilde özetlemiştir:

1-Kitsch yüksek duygusal yoğunluğa sahip nesneleri ya da temaları tasvir eder.

2-Kitsch tarafindan tanımlanan nesneler ya da temalar hemen ve çaba sarf etmeden ayırt edilebilir. 
3-Kitsch, tasvir ettiği nesnelerle ya da temalarla ilgili çağrışımlarımızı temel ölçekte zenginleştirmez (Kulka, 2014. 57).

Kitsch ile ilgili bu sıralanan maddeler dışında ortak bir şey söylemek güçtür çünkü esnek ve kültüre bağlı bir kavramdır. Kitsch, kültürel tarihsel ve toplumsal olarak değişime açıktır. Bir toplum ya da zaman dilimi için Kitsch sayılabilecek bir şey, bir başka toplum ya da zaman diliminde Kitsch olmayabilir. Bu bakımdan kischin sınırlarını belirlemek mümkün değildir. Bununla birlikte Kulka’ya (2014) göre, Kitsch sayılan üretimler içinde de dereceler söz konusudur. Bazı ürünler bir diğerine göre daha fazla Kitsch olabilmektedir.

\section{Kitsch Müzik}

Kitsch, dergi kapakları, illüstrasyonlar, reklamlar, çizgi romanlar, Tin Pan Alley müziği, dans müzikleri, müzikaller, popüler müzik örnekleri ve Hollywood filmleri gibi birçok alanda, ticari bir sanat olgusu olarak karşımıza çıkmaktadır. Sanayi devrimi sonrası yeni pazar alışkanlıkları içinde, tüketici taleplerini yerine getirmek için tasarlanmış üretimi imlemektedir. Kültür endüstrisi, orijinal kültüre ait değerlere duyarsız ancak kültürün sağlayabileceği çeşitlenmelere gereksinim duyanlara yönelik bir üretim biçimidir.

Kitsch'in kitle kültür içindeki bu yeri göz önüne alındığında, resim, heykel, sinema veya fotoğraf gibi alanlardaki kullanımının yanında, müzikteki anlamı da önemli bir konuyu ifade etmektedir. Bu bağlamda çalışmanın bu aşamasında Kitsch'in müziksel bir karşılığının olup olmadığı incelenmek istenmektedir.

Doğası gereği hafif, bayağı ya da çirkin müzikle bir tutmak müziksel Kitsch’i ya da Kitsch müziği açıklamakta tercih edilen bir yöntemdir. Bu yönteme endüstriyel müzikten, popa; folklorik müzikten, kendi döneminin estetik anlayışına uygun olmayan birçok müzik türünden örnekler vermek mümkündür. Bununla birlikte söz edilen müzik türleri içinde, Kitsch'e ait bir üretim biçimiyle hiçbir ilişkisi olmayan örnekler bulmak da mümkündür. Bu nedenle bir müziğin kendisini ya da onun türsel anlamdaki üst başlığını bütünüyle Kitsch'le ilişkilendirmek, onu oldukça sınırlı bir alana çekmek anlamı taşımaktadır.

Kitsch müziği örneklendirmek isterken endüstri devrimi sonrası, yeniden ya da seri üretilebilirlik çağında, Benjamin'in değişiyle “aura”sını kaybetmiş ürünleri göstermek mümkündür. Bu bağlamda ele alındığında, popüler müzik de 'aurasını yitirmiş bir müzik' olarak ifade edilebilir. Popüler müzik, müzik üzerine önemli çalışmalar yapmış olan fillozof, besteci ve müzikolog Theodor Adorno'dan bu yana birçok akademik çalışmanın odağı haline gelmiştir.

1930'ların sonlarında Frankfurt Okulu'nun önde gelen iki üyesi, T. W. Adorno ve Max Horkheimer, 'kültür endüstrisi' (ayrıca 'eğlence endüstrisi' gibi tanımlarla da dile getirilen) fikrini ortaya attılar ve savaş sonrasındaki (ilk kez 1947'de yayımlanmış) ortak çalışmaları olan Aydınlanmanın Diyalektiği'nde bunu daha geniş bir bakış açısından ve daha ayrıntılı bir şekilde çözümlediler (Calinescu, 2010: 266).

Adorno'ya göre, kültür endüstrisi toplumu eğlence standardizasyonu yoluyla kontrol etmeyi amaçlayan bir sistemdir. Kültür endüstrisi genel olarak kültürle ilişkili tüketim pazarına rahatlık getirecek ürünler sağlamaktadır. Bu ürünler pazar içindeki konumları gereği kolay ulaşılabilir ve tüketimi arttırıcı nitelikte olmalıdır. Kitleler, üretimlerin biçimleri bakımından kafa dağıtmaya ya da eğlenceye ihtiyaç duyar hale gelmişlerdir. Bu anlamda zaten mekanize edilmiş işlerle boğuşan kitlesel tüketiciler, boş zamanlarında zevklerini şekillendir ve böylece uygun davranışı teşvik etmek için bilinçlerini kontrol altına alan sanayileşmiş eğlencenin insafına kalmışlardır. Adorno eğlence kültürü ile ilgili düşüncelerini şu şekilde dile getirmiştir:

İnsanlar eğlenmek isterler. Aşırı yoğunlaşmış ve bilinçli bir sanat deneyimi sadece yaşamları aşırı sıkıntıyla geçmeyen, boş zamanlarında hem sıkıntı hem de çabadan kurtulmak

\section{Turkish Studies}

Volume 14 Issue 6, 2019 
istemeyenler için mümkündür. Ucuz ticari eğlencenin tamamı bu ikili arzuyu yansıtır. Rahatlamayı sağlar çünkü kalıplanmış ve önceden hazmedilmiştir (Adorno'dan aktaran Calinescu, 2010: 267).

$\mathrm{Bu}$ şekilde üretim biçimi sadece belli metaları değil aynı zamanda bu metaları talep edecek ihtiyacı da üretmektedir. Adorno'ya göre popüler müzikte de tam da böyle bir üretim biçiminin yapılandırdığı bir eğlence kültürünün ürünüdür. “Adorno'nun popüler müzikle ilgili üç önemli tespiti söz konusudur. Bunlardan ilki, bu müziğin tekrarlanan şematik motiflere dayanmasıdır. İkincisi, akı1 dışı bir tüketimi teşvik etmesi ve sonuncusu da özellikle gençlerin modern yaşam mekanizmalarına daha kolay uyum sağlamasına olanak tanıyan sosyal bağlayıcı olarak hizmet etmesidir" (Babilas, 2014: 116). Bu bağlamıyla ele alındığında Adorno'ya göre popüler müzik bir Kitsch müzik örneğidir.

Kitsch yanlış bilinçliliğin mükemmel bir aracıdır. Adorno’ya göre müzikal gerçeklik konusu göz önüne alınırsa, Kitsch asla tam olarak kabul edilemez. Kitsch açık bir şekilde, yalan olması yönüyle iyidir. Adorno ayrıca, bu yalan ve yanılsama konusunun tüm sanatlar için geçerli olduğunu söylemektedir (Morris, 2013: 28).

Theodor Adorno'nun Kitsch olarak adlandırdığı müzik, toplumsal baskının gücüyle bir araya gelmekte ve içi boş popüler üretimlere dönüşmektedir. Bu üretimler değişime uygun bir yapıdadırlar. Bununla birlikte müzik endüstrisi ile sırt sırtadırlar ve endüstri ile iş birliği halinde olan bestecilerin çalışmalarıyla ortaya çıkmaktadırlar.

Adorno'ya göre Kitsch müzik, insanların 'kafa dağıtma' isteklerinin bir karş1lığı olarak kitle kültürü tarafından üretilmiş, masum ve doğal bir ihtiyacı gibi gözükse de, bozuk bilinç üreten ve insanların kendi kendilerini kandırmalarına neden olan bir sistemin ürünüdür. Bununla birlikte, bu üretim biçimi sadece popüler müzik ya da düşük sanatla da sınırlı değildir. Adorno'nun çok temel çizgilerle ayırdığı müzik kategorileri arasında yeni ve ilerici bir müziğin olanağını ciddi müzikte bulmaktadır fakat Kitsch müzik örnekleri ciddi müzik içinde de görülebilmektedir çünkü bu kategorideki müzikler de kültür endüstrisinin dışında değildir. Ciddi müzik en genel kullanımıyla "Klasik Müziği” ifade etmektedir. Adorno'ya göre böyle geniş bir müziksel kategori içinde eleştirel bir tutumu ortaya koyamamış ve sadece burjuva kültürünün müzik-estetik alışkanlıklarının devamı niteliğinde endüstriyel ürünler de bulunmaktadır. Bu bağlamdaki müziksel üretimler, kültür endüstrisi içinde daima metalaşma tehdidi ile karşı karşıyadır.

Yaygın bir biçimde, çok parlatılmış yorum tarzı olarak oda müziği alanında bile, hafif müzik sayılabilecek şekilde tavizler verilmektedir. Kitlelerin müziksel algıları hafif müzikle doldurulmakta, bu şekilde olmayan diğer müzikal ifade biçimleri de keyfi bir kategori olarak adlandırılmış 'klasik' olarak belirtilmektedir. Ve sadece algısal yetiler her yerde bulunan popüler melodiler tarafindan körermemekte, ayrıca sağlam bir dinleme için gerekli konsantrasyon, bu müzikal çöplerin hafızalardaki izleri nedeniyle es geçilmektedir. Dolayısıyla gerçek bir müziksel alılmama imkânsız bir hal almaktadır... Müzik, Clement Greenberg'in tüm sanatın Kitsch ve avant-garde'a bölünmesi olarak adlandırdığı şeyle açıkça bağlantılıdır. Kitsch, toplumu ele geçirdiğinden bu yana, kültür üzerinden sağlanan kazancı ifade etmektedir (Adorno, 2004: 10).

Kitsch müziği sadece hafif-düşük müzik düşüncesiyle bir tutmak yetersiz olacaktır. Kitsch de sadece düşük bir sanatsal düşüncenin ifadesi değildir. "Kitsch'in aynı zamanda yüksek formları vardır ve Broch'un sözleriyle Kitsch'te Wagner gibi, Tchaikowsky gibi dehalar vardır" (Nerdrum, 2010:11). Adorno'ya göre Elgar ve Sibelius'un müziklerini de Kitsch'e örnek olarak gösterilebilmektedir. Aslında Kitsch, ciddi müzik olarak nitelendirilen kategori içinde Adorno'nun örnek verdiği sadece bu bestecilerin müzikleriyle sınırlı değildir. Yeni yüzyılla birlikte modern zamanlarla uyuşamayan Tchaikowsky, Puccini, Rachmaninov, Gershwin ve pek çok bestecinin müzikleri için de bu tanım kullanılmıştır. Bu bestecilerin eserlerinin birçoğu Kitsch olarak nitelendirilmiştir. Günümüzün sanatsal perspektifiyle kitcsh konusu ele alındığında aslında bu bestecilerin müzikleri oldukça masum

\section{Turkish Studies}

Volume 14 Issue 6, 2019 
kalmaktadır. Monelle'ye (2013) göre, Chichester İlahileri'ni, Concierto de Aranjuez'i ya da Yıldız Savaşları'nın temaları göz önüne alındığında, bütün bu müzikleri kucaklayan bir kategori olarak 'klasik müziğin' endüstriyel bir bozuk bilincin kaynağı olduğu anlaşılmaktadır.

Adorno'nun Kitsch olarak nitelediği popüler müziğe bakış açısı bir kenara bırakıldığında, bu müziklerin toplumsal etkilerini de görebilmek söz konusu olmaktadır. Popüler müzik herkes tarafından beğenilmeyebilir ya da sanatsal olarak düşük nitelikte bulunabilir ancak küçük görüldügü noktada onun toplumsallığı da yok sayılmış olacaktır. Sınırlı bir elit zümrenin müzik anlayışı yerine kitleselleşmiş bir müziğin varlığı, popüler müziğin ve şayet onunla eş görülecek olursa, Kitsch müziğin önemini açığa çıkarmaktadır. Bu anlamda popüler müziğin varlığı, ticari ya da sanatsal anlamda düşük nitelikte bulunsa bile, göz ardı edilmemelidir.

Kitsch müziğin temel özelliği insanın duygularını ilgilendiren konulara yönelmesidir. $\mathrm{Bu}$ şekliyle Kitsch müzik insanla dolaysız ilişkili ve yaşama hizmet eder bir haldedir. Bu yönelimi nedeniyle de Kitsch müzik bir propaganda aracı olarak da nitelendirilmiştir. Bu müziğin araçsallaşması onun derin bir ifadeden uzak, kolay anlaşılır olan yapısından kaynaklanmaktadır. Reklam kültürü için ihtiyaç duyulan yapı da budur. Aslında Kitsch müzik, kişinin aklından çok duygularına yönelmektir. Bu da kültür endüstrisinin Kitsch müziği kitleleri etkilemek üzere bir propaganda aracına dönüştürmesini kolaylaştırmıştır.

Kitsch'in güzel sanatlarda ve müzikte ortak olarak geçerli bir önemli özelliği de bir geleneğe öykünüyor ya da taklit ediyor olmasıdır. "Kitsch'in ön koşulu, üretim çeşitliliği içinde bir pazar ilişkisinin, alınıp satılacak bir metanın ve kopyalayabileceği tamamen olgunlaşmış bir kültürel geleneğin varolmasıdır. Pazar içinde taklit edilecek bir gelenek anlayışı kullanılır, dönüştürülür, işe yaramayan kısmı atılır... Üzerinden yeterince zaman geçip de yeni olanlar eskidiğinde, Kitsch olarak hizmet etmeye başlar" (Greenberg, 1989: 10-11).

Müzikle birlikte, orjinaline karşı kopya problemi, modernizmle birlikte teknolojik gelişmelerin bir sonucu olarak ifade edilebilir. Açıkçası, mekanik yeniden üretimin heykeller üzerindeki etkisi ile şarkılar üzerindeki etkisi arasında önemli farklılıklar vardır. Ancak her iki durumda da, tehdidin önemli bir yönü, kopya ile orijinali eşit olarak görme isteğindeki aşırı artış ihtimalinden kaynaklanmaktadır. Bu tür bir artış, bir şey ile onun taklitleri arasındaki ilişkiyi sarsmakla kalmaz, aralarındaki farkı da ortadan kaldırır... Kendimizi, birileri tarafindan yapılmış, muzak'tan disko'ya kadar birçok türde seçilmiş ya da düzenlenmiş Beethoven'ın 5. Senfonisi'nin sayısız kopyalarıyla çevrilmiş bulabiliriz. Aynı şeyi Bob Dylan'ın 'Like a Rolling Stone'ı ya da Gilbert O'Sullivan'ın 'Alone Again (Naturally)'i için de söylemek mümkündür (Morris, 2013: 24-25).

Kitsch, taklit ettiği ya da kopyaladığ örneklerle betimsel ya da simgesel özellikleri üzerinden ilişki kurmaktadır. Bu bağlamda Kitsch olarak ifade edilecek bir üretimin taklit ettiği yönün, taklide kaynaklık eden sanat eserinde açıkça betimlenebildiğini söylemek mümkündür. Oysa soyut sanatta ya da müziğin kendi yapısında bu betimleme ya da simgelemeleri açığa çıkarmak kolay değildir. Yine de bu, soyut sanatta ya da müzikte betimleyici öğelerin olmadığı anlamı taşımamaktadır.

Müzikal eserde betimleyici ve simgesel öğeler yoksa Kitsch de buna paralel olarak mümkün değildir sonucuna varabilir miyiz? Bu soru soyut resim ve soyut heykelde Kitsch olabilir mi sorusuna benziyor. Soyut eserleri, ne kadar kötü olduklarını düşünürsek düşünelim, Kitsch olarak nitelendirmekte güçlük çektiğimizi belirtmiş̧tik. Ama istisnalar yok mu? Kitsch'in parazitsel doğası soyut eserlerde örneklenemez mi? (Kulka, 2014: 142).

Eğer konuyu daha da müzik eksenine getirirsek, bir müzik eserinin simgesel öğeleri apaçık sembolize edilemese de, bazı göndermelere ulaşmak mümkündür. Bir eser, popüler olmuş ya da müzik geleneği içinde daha önce beğenilmiş bir yapıya öyküne bilmektedir. Bu, Kulka'ya (2014) göre, müziğin sanat geleneğinden aldığ 1 bir 'borçtur'. Bir müziğin kendi başına sanatsal ve estetik değeri yoksa ve 
daha önce rağbet görmüş bir yapıdan faydalanıyorsa, bu onun Kitsch olduğu anlamı taşımaktadır. Asıl olan ve Kitsch ile ilgili olmazsa olmaz koşul da budur. Kitsch müziğin doğası parazitsel ilişki içinde olduğu kaynağı ya da geleneğiyle birlikte görünüme gelmektedir. Diğer taraftan her müziksel alıntı ya da öykünmenin de Kitsch'i ortaya çıkarmadığını da vurgulamak gerekmektedir. Kulka bu konuda şu örnekleri vermektedir:

Örneğin, diğer eserlere gönderme yapmayı (başka bestecilerinkine olduğu kadar kendi eserlerine de) ve müzikal tema alıntılamayı neredeyse saplantı haline getiren Dmitry Shostakovich'i düşünelim. Bestecinin On beşinci Senfonisi, Rossini'nin William Tell uvertürü ile finalde Wagner'in The Ring eserindeki "Kader" motifi üzerine inşa edilmiştir. Önemli olan nokta şudur; On beşinci Senfoninin güzelliği eserin Rossini'nin ya da Wagner'in eserleri üzerinden beslenmesinden ya da Shostakovich'in önceki başarılarından kaynaklanmaz. Alıntılanan müzikal temaların esere entegrasyonu ve dönüşümleri kendi güzelliklerini yaratır, "ödünç alınan," kısımlar yeni müzikal bağlamla olan etkileşimleriyle yeni anlamlar kazanıp, zenginleşmiştir. Kitsch müzik ise ödünç aldığı müzikal temaları sadece sulandırıp, duygusallaştırır (Kulka, 2014: 144).

Kulka'ya (2014) göre, bir başka Kitsch müzik örneği de Tchaikowsky'nin '1812 Uvertürü'dür. $\mathrm{Bu}$ eserde de müzikteki simgesel öğeleri anlamak güçtür. Yine de betimleyici öğeleri seçebilmek mümkündür. Tchaikowsky eserinde betimleyici imler içeren bölümler kullanmıştır. Örneğin Marseillaise alıntısı, Moskova'nın çanları, kanonlar ve savaş trompetleri gibi alıntılar, dinleyicide hazır bulunan duygulara yönelmiş çağrışımlar ve biçimsel öğeler olarak anlaşılmaktadır.

Kitsch müziğin bir başka özelliği de, özellikle popüler müzikte karşılaşılan basitlik karakteridir.

Şarkılar, genellikle daha önce beğeni görmüş müzikal yapılar üzerinden şekillenir. Duygusallığın yanı sıra basitlik de karakteristik özellikler arasındadır. Kitsch müzik nadiren karmaşık yapıya sahiptir ve ciddi müziğin özelliklerinden olan özgünlük ve estetik yoğunluk Kitsch müzikte yoktur. Temel ton ya da tema yukarıda belirtilenleri yerine getirdiği müddetçe, temanın ve tonun nasıl aktarıldığı ve enstrümanlar ikinci planda kalır (Kulka, 2014: 143-144).

Kulka'nın bu açıklamalarına ek olarak, Kitsch'e örnek gösterilebilecek günümüz popüler müziği için de şunlar söylenebilmektedir:

- Hipnonik bir etki yaratan, sürekli tekrar eden müzik bölümleri ya da sözleri içermesi.

- Karmaşık olmayan, az formlu ve basit armonik dizilimli yapılarla oluşturulması.

- Basit ve tekrara dayalı dijital altyapılar kullanılması.

- Teknolojik imkânlarla müziğin altyapısının çok önüne getirilmiş vokal sesleri kullanılması.

\section{Sonuç}

Bu çalışmada Kitsch'in güzel sanatlar alanıyla ilişkisi olan yapısı hakkında şu sonuçlara ulaşılmıştır:

Kitsch temel olarak 20. yy'ın kültür yaşantısıyla ilgili önemli bir olgudur fakat kökeninin 20.yy'dan çok daha öncelere dayandığını da söylemek mümkündür. Bu tür bir üretim güzel sanatlarla ilgili yerleşik bir sanat geleneğiyle parazitsel ilişki kurarak yapılanmaktadır. Gerçek bir sanat alanının özensiz, basit ve kitle kültürünün finansal ilişkilerine hizmet eden, taklit ürünler olarak görünüme gelmektedir. Çoğunlukla dekoratif amaçlı ürünlerde karşımıza çıkmaktadır. Abartılı süslemelerle ve aşırı duygusal ifadelerle kendini belli etmektedir. Büyük kitlelerce, finansal anlamda kolay ulaşılabilir niteliktedir. Kitlelerin Kitsch yönelmelerinin bir diğer sebebi de kolay anlaşılabilir olmasıdır. Kitsch somut ve simgesel niteliktedir ve bu yapısı potansiyel alıcısının duygu ve isteklerine göre şekillenmiştir. Son olarak, Kitsch'i sadece kötü sanatla bir tutmanın da doğru bir yaklaşım olmadığını söylemek gerekmektedir. Bu bağlamda, söz edilen nitelikler dışında kalan her kötü sanat Kitsch değildir. 
Çalışmanın temel amacı olan 'Kitsch müziğin yapısının ve özelliklerinin açıklanması' konusunda şu sonuçlara ulaşılmıştır:

Müzik alanında Kitsch, varlığını güzel sanatlardaki gibi ortaya koyan bir olgudur. Bununla birlikte, Kitsch'in somut ve simgesel niteliği nedeniyle, müzikte, güzel sanatlarla ilişkili örneklerine göre daha zor anlaşılabilmektedir. Müzik, seslerle örülmüş doğası gereği soyut anlatımlara içkin bir yapıdadır ancak bu, müziğin simgesel ya da betimsel içeriğe sahip olmadığı anlamı taşımamaktadır. Müziğin anlatımsal dili somut ifadeleri de içerebilmektedir. İşte bu yönü Kitsch'in müzikteki karşılığının oluşmasının temel nedenidir.

Kitsch müzik de tıpkı diğer sanatlarla ilişkili örneklerinde olduğu gibi basit yapılanmış, kolay anlaşılabilir ve büyük kitlelerin duygu ve isteklerine yönelmiş niteliktedir. Yine yerleşik bir müzik geleneğine öykünür ve onu taklit eder. Büyük kitlelerin oyalanma ve eğlenme istekleri endüstri devrimi ile birlikte kolay ulaşılabilir bir müzik anlayışını ortaya çıkarmıştır. Popüler ya da hafif müzik olarak ifade edilebilecek bu müzik düşüncesi ciddi müziğin araç ve yapılarını kullanmış bir üretim biçimini imlemektedir. Konuyu bu bağlamıyla ele alan birçok yaklaşım, Kitsch müziği popüler müzikle bir tutmaktadır. Popüler müzik hem üretim biçimi ve niteliği hem de kitleselleşme özelliği nedeniyle Kitsch'le eş görünümdedir ancak Kitsch müziğin popüler müzikten daha geniş bir alanı ifade ettiğini söylemek mümkündür. Ciddi müzik ya da yüzelsel bir kategori olarak 'klasik müzik' içinde de Kitsch müzik örnekleri vardır. Aynı şekilde etnik müzik örneklerinde de Kitsch rastlanmaktadır. Bu bağlamda kullanım genişliği ve esnekliği nedeniyle Kitsch'e birçok farklı müzik alanında rastlanılabileceği sonucuna ulaşılmıştır.

\section{KAYNAKÇA}

Adorno, T. W. (1998). Quasi Una Fantasia: Essays on Modern Music, London: Verso.

Adorno, T.W. (2004). Philosophy of Modern Music, New York: The Continuum Publishing,

Adorno, T. W., Leppert, R. (2002). Essays on Music, California: University of California Press.

Babilas, D. (2014). "Art and Kitsch in Brian de Palma's Phantom of The Paradise". Justyna Stepien (Ed.), Redefining Kitsch and Camp in Literature and Culture içinde (s. 115-128). UK: Cambridge Scholars Publishing.

Bala, I. (2016). "Interpreting Chopin's Music Today: Mythologization of Art: Kitsch", International Journal of Humanities and Social Sciences, 10(3), 1042-1045.

Benjamin, W. (2008). "Dream Kitsch Gloss on Surrealısm". M. W. Jennings, B. Doherty ve T. Y. Levin (Ed.), The Work of Art in The Age of Its Technological Reproducibility, and Other Writings on Media içinde (s. 236- 239). London: Harvard University Press.

Calinescu, M. (2010). Modernliğin Beş Yüzü: Modernizm, Avangard, Dekadans, Kitsch, Postmodernizm. S. Gürses (Çev.). İstanbul: Küre Yayınları.

Dorfles, G. (1973). Kitsch: An Anthology of Bad Taste, London. Studio Vista.

Greenberg, C. (1989). “Avant-Garde and Kitsch”. Artand Culture: Critical Essays. Boston: Beacon Press.

Greenberg, C. (2015), “Avangart ve Kitsch”. M. Yalçın (Çev.). Melamet Dergisi, 1, 44-49.

Kulka, T. (2014). Kitsch ve Sanat, (Çev: G. Gülbey), İstanbul: Altıkırkbeş Basın Yayın.

Limon, B. (2012). "Kültürel Değişim Sürecinde Popüler Kültür ve Kitsch Kavramı”, İdil Sanat ve Dil Dergisi, 1 (3),106-115. 
Monelle, R. (2013). "Musica Speculativa and The Nexus of Music and Nature" In Conference on Music Semiotics.

Morris, M. (2013). The Persistence of Sentiment: Display and Feelingin Popular Music of The 1970s. California: University of California Press.

Nerdrum, O. (2010). Kitsch Üzerine, (Çev: A. F. Konur), İstanbul: Küre Yayınları.

Prato, P. (1985). "Musical Kitsch: Close Encounters Between Pops and Classics", Popular Music Perspectives, 2, 375-386.

Şahin, H. (2016).“Sanatta Kitsch Olgusu Üzerine”, Akdeniz Sanat Dergisi, 9 (17), 1-27. 